\title{
Multimodal monitoring does not decrease renal or cardiac impairment after major abdominal surgery
}

Matej Jenko, Katarina Mencin, Neva Požar Lukanovič, Vesna Novak Jankovič, Alenka Spindler Vesel

Corresponding author: alenka.spindler@guest.arnes.si

University medical centre Ljubljana, Department of anaesthesiology and surgical intensive therapy, Zaloška 7, SI-1000 Ljubljana

\section{Background and goal of study}

The combined use of new monitoring methods during anaesthesia (monitoring blood flow with assessment of fluid status and regional tissue oxygenation) with adherence to appropriate management protocol might radically improve perioperative outcome of high-risk surgical patients. Only few studies have showed the effect of multimodal monitoring on mortality and complications. Our study presents very homogenous groups of patients undergoing major abdominal surgery, with similar perioperative management and anaesthesia technique. The goal is to assess the differences in incidence of postoperative acute kidney injury and myocardial infarction if the multimodal monitoring is being used intraoperatively.

\section{Materials and methods}

Prospective, randomised trial with 2 parallel groups was conducted at the University medical centre (UMC) Ljubljana in years 2015 - 2017. ASA 2-3 high risk surgical patients that underwent major abdominal procedures were included. The study was approved by the national medical ethics committee of Slovenia. In control group, only conventional monitoring was used, but in the multimodal group, intraoperative fluid status was optimised according to blood flow monitoring and tissue oxygenation according to cerebral oxygenation monitoring. Postoperatively, clinical examination and laboratory values (including creatinine and troponin I) were conducted every 24 hours first three days. Acute kidney injury was suspected if $\geq 0.3 \mathrm{mg} / \mathrm{dL}$ increase in creatinine level or 1.5 times baseline (KIDGO stage 1). Myocardial infarction was suspected if troponin I was positive according to laboratory reference range.

\section{Results and Discussion}

\begin{tabular}{|c|c|c|c|}
\hline $\begin{array}{c}\text { Lee's Revised Cardiac } \\
\text { Risk Index }\end{array}$ & $\begin{array}{c}\text { Control group } \\
\text { (number of patients) }\end{array}$ & $\begin{array}{c}\text { Multimodal group } \\
\text { (number of patients) }\end{array}$ & $\begin{array}{c}\text { P value (Chi - square } \\
\text { or Fisher exact test) }\end{array}$ \\
\hline II & 26 & 27 & 0.855 \\
\hline III & 12 & 10 & \multirow{2}{*}{0.500} \\
\hline $\begin{array}{c}\text { IV } \\
\text { (KISe in creatinine level }\end{array}$ & 3 & 4 & 0.247 \\
\hline $\begin{array}{c}\text { oliguria (urine output } \\
\text { less than 500mI) } \\
\text { in first 3 days }\end{array}$ & 1 & 3 & 0.241 \\
\hline rise in troponin level & 0 & 3 & 5 \\
\hline
\end{tabular}

There were no clinical signs of myocardial infarction in patients with raised troponin. Median intraoperative fluid load was higher in multimodal group (1650 vs $900 \mathrm{ml}, \mathrm{p}=0.000$, Mann-Whitney U test).

At first glance, we can conclude that combination of hemodynamic monitor and measurement of cerebral oxygenation do not provide benefit to patients in our study. However, subsequent analysis has showed that there are some postoperative complications such as need for revision surgery, additional antibiotic treatment required third day after procedure or re-admission to HDU that occur only in control group.

\section{Conclusion}

In our study, combined use of hemodynamic monitoring and cerebral monitor does not significantly decrease the incidence of renal or cardiac impairment after major abdominal surgery. 